\title{
Melting and Solidification Heat Transfer Characteristics of a Phase-Change Material in a Latent Heat Storage Vessel: Effects of a Perforated Partition Plate and Metal Fiber
}

\author{
Than Tun Naing ${ }^{1}$, Akihiko Horibe ${ }^{1}$, Naoto Haruki ${ }^{2}$, Yutaka Yamada1 \\ ${ }^{1}$ Graduate School of Natural Science and Technology, Okayama University, Okayama, Japan \\ ${ }^{2}$ Department of Human Information Engineering, Okayama Prefectural University, Okayama, Japan \\ Email: pslg3e8s@s.okayama-u.ac.jp, horibe@okayama-u.ac.jp, haruki@ss.oka-pu.ac.jp,y.yamada@okayama-u.ac.jp
}

How to cite this paper: Naing, T.T., Horibe, A., Haruki, N. and Yamada, Y. (2017) Melting and Solidification Heat Transfer Characteristics of a Phase-Change Material in a Latent Heat Storage Vessel: Effects of a Perforated Partition Plate and Metal Fiber. Journal of Power and Energy Engineering, 5, 13-29.

https://doi.org/10.4236/jpee.2017.58002

Received: July 4, 2017

Accepted: August 7, 2017

Published: August 10, 2017

Copyright () 2017 by authors and Scientific Research Publishing Inc. This work is licensed under the Creative Commons Attribution International License (CC BY 4.0).

http://creativecommons.org/licenses/by/4.0/

\begin{abstract}
Today, latent heat storage technology has advanced to allow reuse of waste heat in the middle-temperature range. This paper describes an approach to develop a latent heat storage system using middle-temperature waste heat $\left(\sim 100^{\circ} \mathrm{C}-200^{\circ} \mathrm{C}\right)$ from factories. Direct contact melting and solidification behavior between a heat-transfer fluid (oil) and a latent heat storage material mixture were observed. The mixture consisted of mannitol and erythritol $\left(C_{\mathrm{m}}\right.$ $=70$ mass $\%, C_{\mathrm{e}}=30$ mass \%) as a phase-change material (PCM). The weight of the PCM was $3.0 \mathrm{~kg}$ and the flow rate of the oil, $f_{\mathrm{oil}}$, was $1.0,1.5$, or 2.0 $\mathrm{kg} / \mathrm{min}$. To decrease the solidified height of the PCM mixture during the solidification process, a perforated partition plate was installed in the PCM region in the heat storage vessel. PCM coated oil droplets were broken by the perforated partition plate, preventing the solidified height of the PCM from increasing. The solidification and melting processes were repeated using metal fiber. It was found that installing the metal fiber was more effective than installing the perforated partition plate to prevent the flow out problem of the PCM.
\end{abstract}

\section{Keywords}

Heat Storage Vessel, Solidified Height, Phase-Change Material (PCM), Mixture, Perforated Partition Plate, Metal Fiber

\section{Introduction}

In recent years, various energy crises have occurred. The difference in electric 
power consumption between day and night is high. To solve this problem, thermal energy storage technology is one of the effective ways to allow recovery and use of various alternative energy sources, such as factory waste heat, solar energy, and off-peak electricity. The advantages of latent-heat storage systems are that their charging and discharging functions occur at an almost constant temperature and they have the large heat-storage capacity.

In several industrial processes, where a great amount of waste heat could be reused by means of a waste heat recovery system; in many cases, the heat availability period differs from its usage period, and not having a storage system means all that excess energy, unusable at the moment of generation, will be simply wasted. Industrial waste heat is stored in the form of latent heat by melting the PCM, which is then transported to office buildings, hospitals, hotels, etc., in a container car. It has been used in a heating system for houses and apartments as desirable places and desirable time by storing and transporting the wasted heat energy from factories.

In most latent heat storage systems, a multi-tube direct contact heat exchanger is used. A direct contact heat exchanger can exchange energy more rapidly than an indirect contact heat exchanger. A spray tower-type direct contact heat exchanger using a phase-change material (PCM) (tetradecane) in low-temperature regions and air has been studied experimentally [1]. The heat transfer characteristics of a direct contact evaporator of a two-phase refrigerant have also been studied [2]. Performance of a direct contact latent heat energy storage system during the discharging process has been investigated using a storage medium of sodium thiosulfate pentahydrate [3]. The thermal and flow behavior in a transheat $(\mathrm{TH})$ container has been examined, in which the solidification and melting of the PCM were observed directly using a two-dimensional roundly sliced model [4]. The improvement in heat storage performance of a direct contact heat exchanger using the phase-change material erythritol and heat transfer oil was described [5].

A series of binary systems of palmitic acid (PA) and stearic acid (SA) in different proportions was prepared from liquid mixtures by slow cooling to room temperature to determine the eutectic mixture ratio. After determining of the eutectic composition ratio of the (PA/SA) binary system, its thermophysical properties were measured with differential scanning calorimetry (DSC). Next, the phase transition characteristics of the mixture, such as the total melting and solidification temperatures and times, were established [6]. Erythritol-polyalcohol mixtures were prepared as PCMs, which may be applicable for heat storage in the temperature range between $80^{\circ} \mathrm{C}$ and $100^{\circ} \mathrm{C}$, for a hot water supply system. The melting and solidification temperature was adjusted by adding polyalcohols, such as trimethylolethane (TME), 2-ethyl-2methyl-1,3-propanediol, 2-amino-methyl-1,3-propanediol-1,4-butanediol,2-amino-1,3-propanediol, and trimethylolpropane (TMP), to erythritol [7]. A eutectic composition with a melting temperature of $363^{\circ} \mathrm{C}$ was determined as ( $\mathrm{mol} \%$ ) $\mathrm{LiF}$ (17.4), $\mathrm{LiCl}(42.0)$, 
$\mathrm{LiVO}_{3}$ (17.4), $\mathrm{Li}_{2} \mathrm{SO}_{4}$ (11.6), and $\mathrm{Li}_{2} \mathrm{MoO}_{4}$ (11.6) [8]. The direct contact melting and solidification behavior between heat transfer oil and erythritol (PCM) were visualized to investigate the characteristics of heat storage and release at different flow rates of oil $(1.0-4.0 \mathrm{~kg} / \mathrm{min})$ and the effects of a perforated partition plate [9].

In this study, we investigated the melting and solidification characteristics of mixtures of mannitol and erythritol ( $C_{\mathrm{m}}=70$ mass $\%, C_{\mathrm{e}}=30$ mass $\%$ ) for latent heat storage at about $\left(100^{\circ} \mathrm{C}-200^{\circ} \mathrm{C}\right)$. The melting point and latent heat of mannitol are $T_{\mathrm{m}}=168^{\circ} \mathrm{C}$ and $L_{\mathrm{m}}=301.2 \mathrm{~kJ} / \mathrm{kg}$, respectively. The melting point and latent heat of erythritol are $T_{\mathrm{e}}=119^{\circ} \mathrm{C}$ and $L_{\mathrm{e}}=340 \mathrm{~kJ} / \mathrm{kg}$, respectively. The mixture of mannitol and erythritol had melting temperatures [latent heat] of $T_{\mathrm{m} 1}$ $=103^{\circ} \mathrm{C}\left[L_{1}=81 \mathrm{~kJ} / \mathrm{kg}\right], T_{\mathrm{m} 2}=151^{\circ} \mathrm{C}\left[L_{2}=201 \mathrm{~kJ} / \mathrm{kg}\right]$. The melting temperature and latent heat of the mixture were measured using a DSC device [10]. The specific heat of the heat transfer fluid oil is $1.63 \mathrm{~kJ} / \mathrm{kgK}$ at $100^{\circ} \mathrm{C}$ (Table 1 ). The specific heat of the heat transfer oil value that used in this experiment at constant and ignore the effect of temperature change in specific heat. Figure 1 shows the Annual discarded waste heat by various industrial sectors in Japan [11]. In this graph, most of the waste heat energy is at about $150^{\circ} \mathrm{C}$. To store this waste heat energy, this paper describes an approach to develop a latent heat storage system using middle-temperature waste heat $\left(\sim 100^{\circ} \mathrm{C}-200^{\circ} \mathrm{C}\right)$ from factories. And the target temperature of heat storage material is $150^{\circ} \mathrm{C}$. Sugar alcohols such as erythritol and mannitol are both chemically stable in both substances and are extremely harmless to the human body as it is also used in sweeteners. Also, it has high latent heat and is relatively inexpensive, it is considered to be a material suitable for latent heat storage material. We compared the melting and solidification characteristics of the mixture with and without a perforated partition plate, and with aluminum metal fiber.

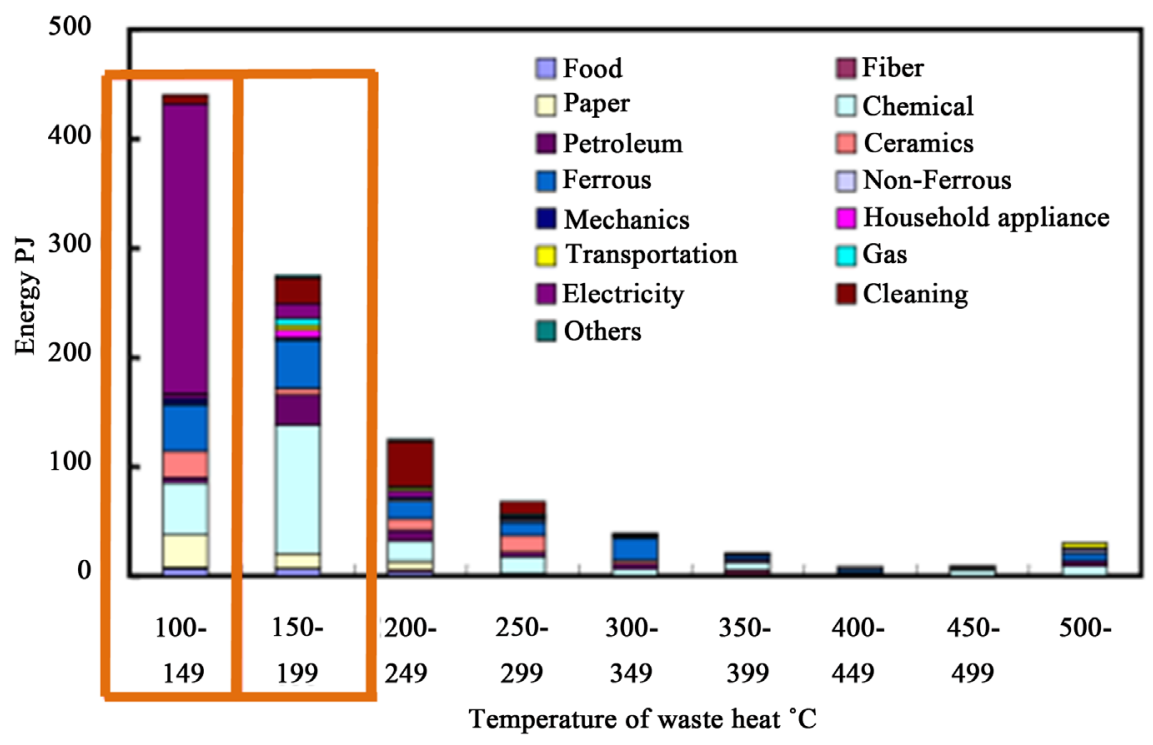

Figure 1. Annual discarded waste heat by various industrial sectors in Japan. 


\section{Experimental Apparatus and Methods}

The experimental apparatus consisted of a heat storage vessel, high- and lowtemperature oil baths (heating capacity: $2 \mathrm{~kW}$; T301; Thomas Kagaku), a heat exchanger, a chiller (cooling capacity: $4.5 \mathrm{~kW}$ ), pressure gauges (measuring range: -0.1 to $0.3 \mathrm{Mpa}$ ), a digital camera, a pump (MMH21; Sanwa Pump), Ktype thermocouples, a digital weighing machine, and a data logger to collect the changed temperature histories. The accuracy of temperature measurements was $\pm 0.2^{\circ} \mathrm{C}$. It means the data logger measurement accuracy. The size of heat storage vessel (width $\times$ length $\times$ height) was $300 \times 80 \times 510 \mathrm{~mm}$ and the thickness of the test section was $6 \mathrm{~mm}$. The experimental apparatus is shown in Figure 2. Figure 3 shows details of the heat storage vessel. After oil passed through a nozzle plate at the bottom of the test section, oil flowed in the upward direction, through the PCM region, and exchanged heat directly with PCM. The nozzle plate has 24 holes and its diameter is $1.6 \mathrm{~mm}$ as in Figure 4. Figure 5 shows the perforated partition plate and metal fiber. Pyrex glass wool (10 $\mathrm{mm}$ thickness) was used on both sides of the heat storage vessel, allowing photos to be taken of the PCM's

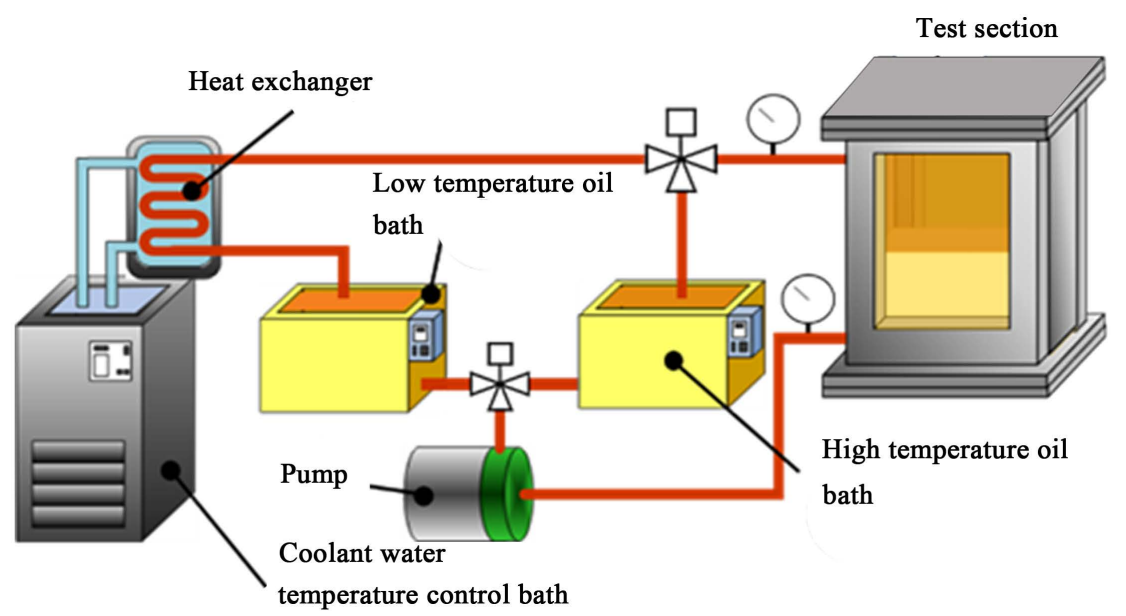

Figure 2. Schematic diagram of the experimental apparatus.

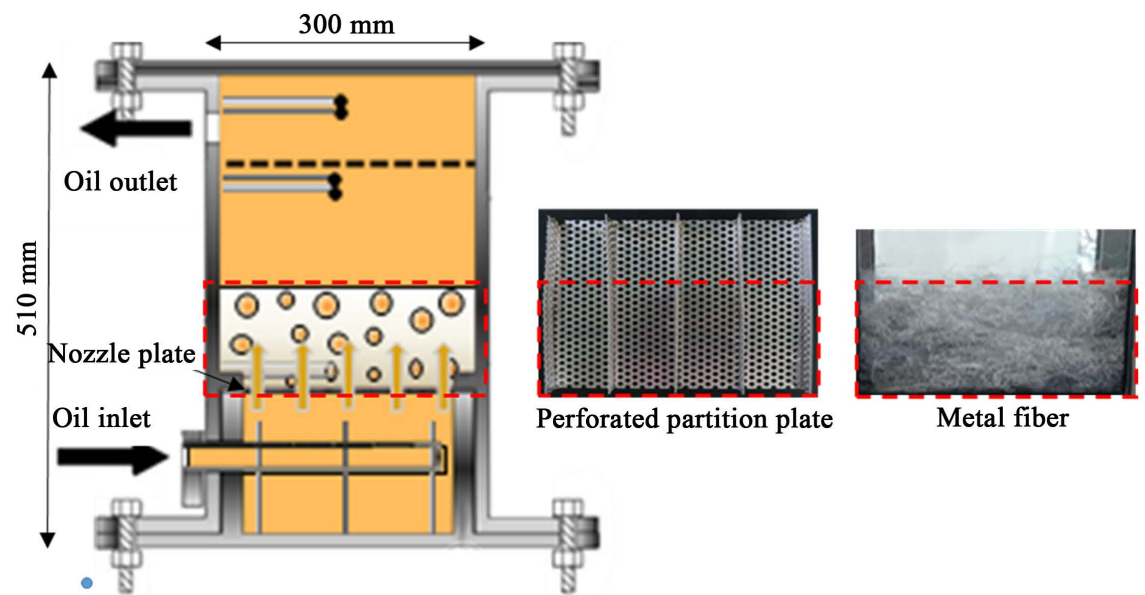

Figure 3. Details of the heat storage vessel. 


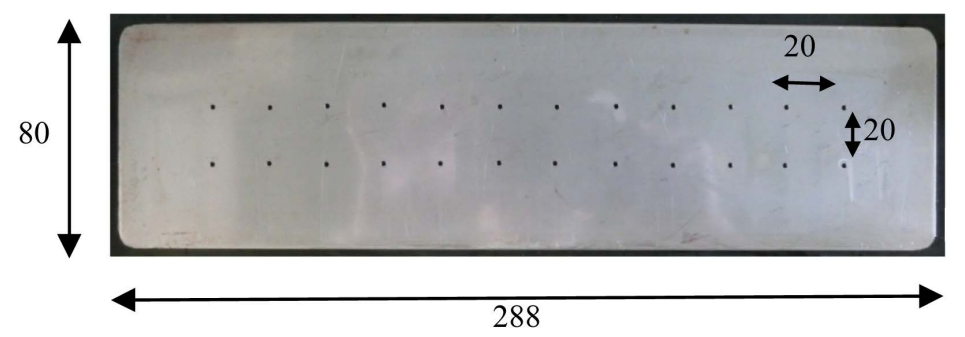

Figure 4. Nozzle plate.

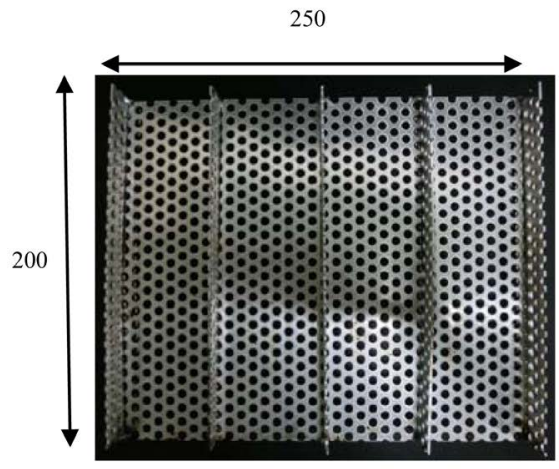

Front view of plat

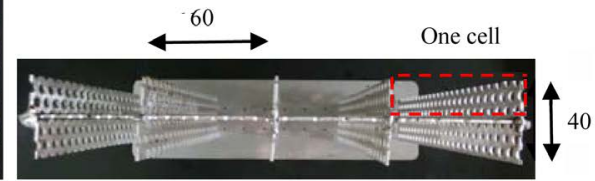

Top view of plate

(a)

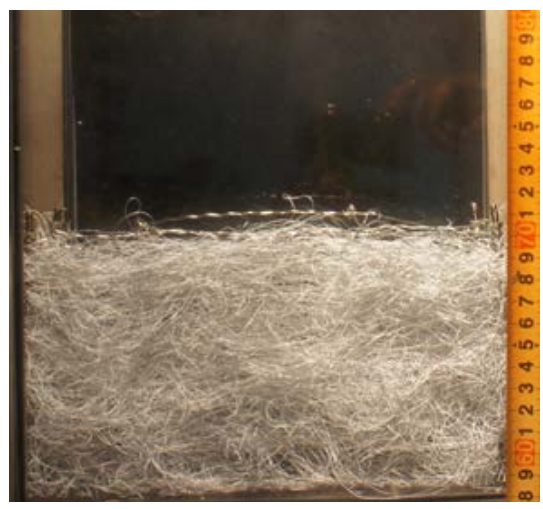

(b)

Figure 5. (a) Perforated partition plate; (b) Metal fiber.

condition. Ten thermocouples were set in the test section; four thermocouples were placed at the inlet, two in the PCM region, two in the oil region, and two were in the outlet of the test section. The measured temperature data were recorded with a data logger at 15 -s intervals.

The melting and solidification conditions of the PCM in the heat storage vessel were observed using the digital camera. To investigate the effect on the packed height of the PCM during the solidification process, a perforated partition plate was installed in the PCM region in the heat storage vessel. The perforated partition plate was made of an aluminum plate (width $\times$ length $\times$ height) of $40 \times 250 \times 200 \mathrm{~mm}$ and thickness of the plate was $2 \mathrm{~mm}$. The size of one cell of the perforated partition plate was $20 \mathrm{~mm} \times 60 \mathrm{~mm}$ Figure 5 (a). The other 
method tested was use of aluminum metal fiber in the PCM region in the heat storage vessel. The diameter of the aluminum metal fiber was $0.4 \mathrm{~mm}$ and the weight was $90 \mathrm{~g}$ Figure 5(b). If the diameter of the metal fiber is big, it will be less chance to touch the metal fiber and PCM coated oil droplets and it may prevent the breaking of the oil droplets. If the diameter is very small, it may prevent the oil flow, the pressure will be up and the oil pump will be damaged. So the diameter of $0.4 \mathrm{~mm}$ is used. The melting and solidification behavior of the PCM with and without the perforated partition plate and with the aluminum metal fiber were compared.

Before the experiment, the PCM (weight, $3.0 \mathrm{~kg}$ ) was inserted in the heat storage vessel. In the initial conditions of the melting process, all the temperatures of the heat storage vessel, the PCM, and the heat transfer fluid oil in the heat storage vessel were maintained at $90^{\circ} \mathrm{C}$. To melt the mixture in the test section, silicone oil at $200^{\circ} \mathrm{C}$ from the high-temperature oil bath was pumped through the inlet of the heat storage vessel. Then, it flowed upward, through the nozzle plate at the bottom of the heat storage vessel and the PCM region, until the temperature of the mixture increased to $190^{\circ} \mathrm{C}$. The silicone oil was then returned from the outlet of the heat storage vessel to the high-temperature oil bath.

The solidification process started after completion of melting. First, all the temperatures in the heat storage vessel, mixture, and heat transfer fluid oil in the heat storage vessel were maintained at $190^{\circ} \mathrm{C}$. To solidify the mixture, the silicone oil from the low-temperature oil bath at $90^{\circ} \mathrm{C}$ was flowed into the heat storage vessel until the temperature of the mixture decreased to $95^{\circ} \mathrm{C}$. The oil that exited from the outlet port of heat storage vessel passed through the heat exchanger. In the heat exchanger, heat from the oil was exchanged with water from the temperature controlled bath.

In both the melting and solidification processes, oil flowed at a constant mass flow rate. The flow rate of the oil $\left(f_{\text {oil }}\right)$ was measured with the digital weighing machine. These two processes were repeated at different oil flow rates: 1.0, 1.5, and $2.0 \mathrm{~kg} / \mathrm{min}$. Temperature changes during the experiment were recorded with the data logger and the melting and solidification behavior of the latent heat storage mixture were recorded with the digital camera. To decrease the solidified height of the PCM during the process, the perforated partition plate was installed at the PCM region in the vessel. The perforated partition plate was made of aluminum plate Figure 5(a). After finishing the process using the perforated partition plate, the experiment was repeated using the metal fiber with different oil flow rates.

\section{Experimental Results}

\subsection{Solidification Process}

Figure 6 shows the solidification behavior of the PCM with a flow rate of the heat transfer oil of $2 \mathrm{~kg} / \mathrm{min}$. The height of the PCM storage material mixture 


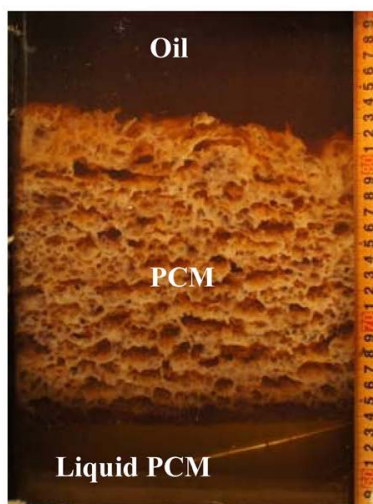

$t=6 \min$

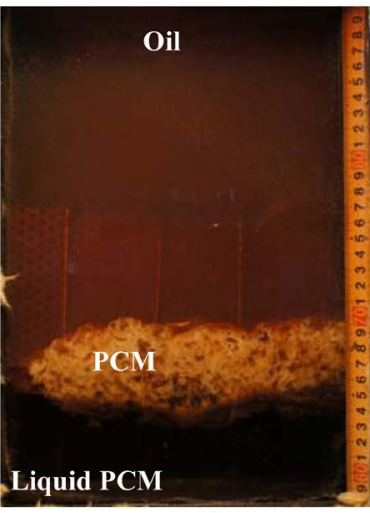

$t=6 \mathrm{~min}$

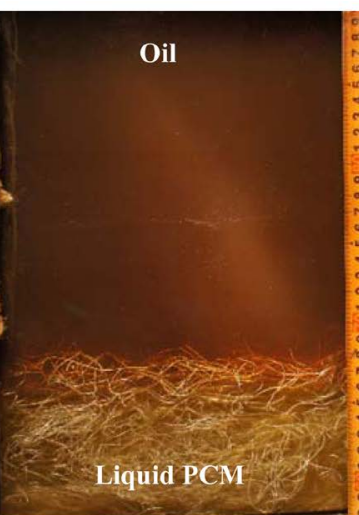

$t=6 \mathrm{~min}$

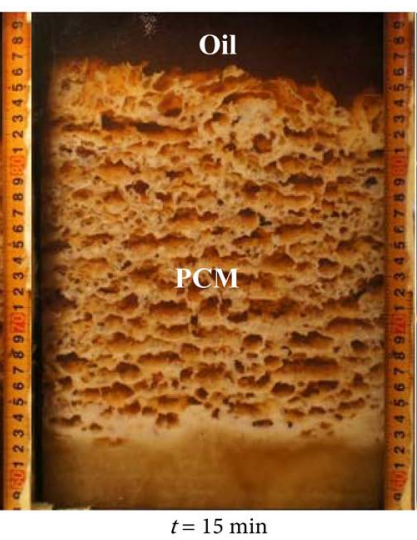

(a)

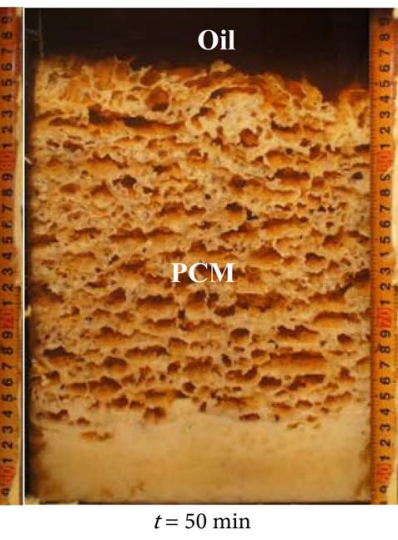

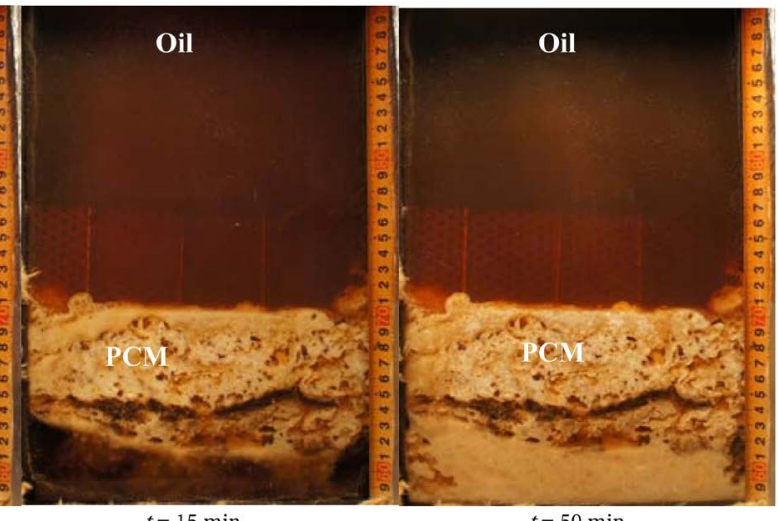

(b)

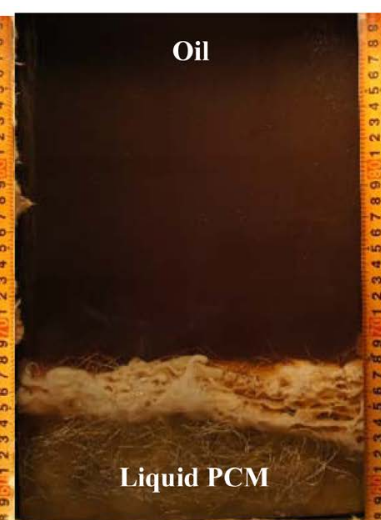

$t=15 \min$

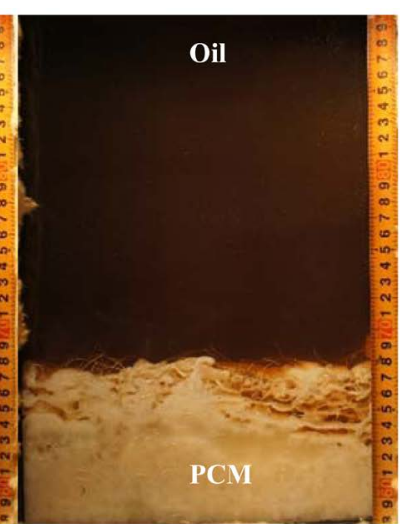

$t=50 \mathrm{~min}$

(c)

Figure 6. Visual observation of the solidification process. This is the photos of PCM's conditions at 6,15 , and $50 \mathrm{~min}$ during the solidification process (a) without perforated partition plate (flow rate of oil $\left[f_{\text {oil }}\right]=2.0 \mathrm{~kg} / \mathrm{min}$ ); (b) with perforated partition plate $\left(f_{\text {oil }}=\right.$ $2.0 \mathrm{~kg} / \mathrm{min})$ and $(\mathrm{c})$ with metal fiber $\left(f_{\text {oil }}=2.0 \mathrm{~kg} / \mathrm{min}\right)$.

was $\sim 80 \mathrm{~mm}$ at the start of the solidification process. Photos were taken at 6,15 , and $50 \mathrm{~min}$ of the solidification process (a) without the perforated partition plate, (b) with the perforated partition plate, and (c) with the aluminum metal fiber. Before starting the solidification process, all temperatures of the heat sto- 
Table 1. Physical properties of mannitol,erythritol, and the heat transfer oil [12].

\begin{tabular}{cccc}
\hline Properties & Mannitol & Erythritol & Oil \\
\hline Latent heat $(\mathrm{kJ} / \mathrm{kg})$ & 303.7 & 340 & - \\
Melting point $\left({ }^{\circ} \mathrm{C}\right)$ & 168 & 119 & 325 \\
Firepoint $\left({ }^{\circ} \mathrm{C}\right)$ & $1.4\left(\right.$ at $\left.20^{\circ} \mathrm{C}\right)$ & $1.48\left(\right.$ at $\left.20^{\circ} \mathrm{C}\right)$ & \\
& $1.38\left(\right.$ at $\left.200^{\circ} \mathrm{C}\right)$ & $1.3\left(\right.$ at $\left.140^{\circ} \mathrm{C}\right)$ & 963 \\
Density $\left(\mathrm{kg} / \mathrm{m}^{3}\right)$ & $1.62\left(\right.$ at $\left.100^{\circ} \mathrm{C}\right)$ & $1.38\left(\right.$ at $\left.20^{\circ} \mathrm{C}\right)$ & $1.63\left(\right.$ at $\left.100^{\circ} \mathrm{C}\right)$ \\
& $2.85\left(\right.$ at $\left.80^{\circ} \mathrm{C}\right)$ & $2.7\left(\right.$ at $\left.140^{\circ} \mathrm{C}\right)$ & \\
\hline
\end{tabular}

rage vessel, the heat transfer oil, and the PCM in the heat storage vessel were maintained at $190^{\circ} \mathrm{C}$ with heated oil from the high-temperature oil bath. Then to start the solidification process, $90^{\circ} \mathrm{C}$ of heat transfer oil was flowed from the low-temperature oil bath to the inlet of the heat storage vessel. Heat transfer oil was flowed through the nozzle plate at the bottom of the heat storage vessel, and then flowed through the PCM region; the oil exchanged heat directly with the PCM in the heat storage vessel. The solidification behavior (a) without the perforated partition plate was as follow. After oil flowed through the nozzle plate, oil droplets became coated by the solidifying PCM as a layer around the oil droplet, and they flowed up to the interface between the PCM and oil. At the interface between the PCM and oil, the oil droplets and the solidified PCM were separated by the density difference between the oil and PCM. The formation of solidified porous PCM increased with time at the interface of oil and PCM. At this time, the solidified PCM formed a porous zone, and the solidification height of the PCM increased. Furthermore, since the initial solidified layer hinders the flow of the oil, and the new solidified porous layer was deposited under the initial solidified layer, and the porous solidified layer became larger. It can be confirmed that it is densely solidified in the lower part of the heat storage vessel.

The solidified height of PCM was $270 \mathrm{~mm}$ (a) without the perforated partition plate, (b) $150 \mathrm{~mm}$ with the perforated partition plate, and (c) $100 \mathrm{~mm}$ with the aluminum metal fiber. In all three cases, the solidified heights of the heat storage PCM material mixture increased with increasing oil flow rate. In (a), without a perforated partition plate, the increase in the solidified height of the heat storage material mixture was larger as $f_{\mathrm{oil}}$ increased. In the solidification process, the solidified height of the PCM was reduced by including the perforated partition plate. The solidified height of the PCM with the aluminum metal fiber was decreased by a further $\sim 50 \mathrm{~mm}$ relative to (b) with the perforated partition plate. The cause of this phenomenon was that the metal fiber was better distributed within the heat storage vessel than the perforated partition plate and metal fiber caused more breakage of the formed oil droplets.

Figure 7 shows the temperature histories without the perforated partition plate at an oil flow rate of $2.0 \mathrm{~kg} / \mathrm{min}$. It indicates the temperatures of the PCM 


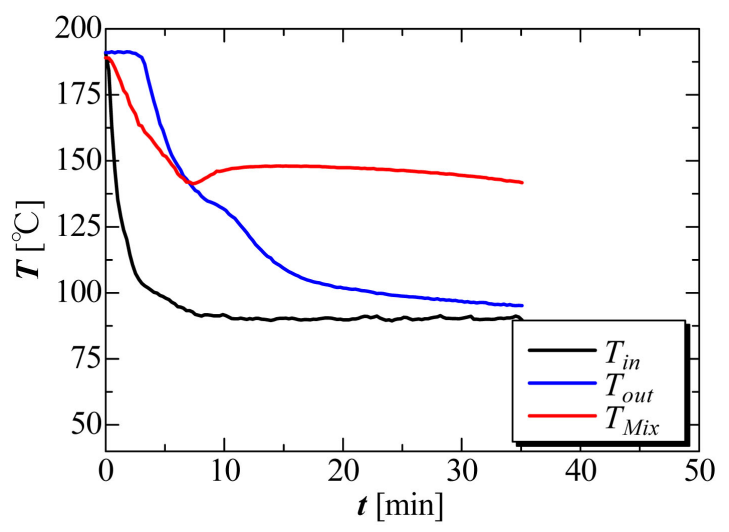

Figure 7. Temperature histories of inlet oil, outlet oil, and the PCM mixture of the solidification process that were recorded using data logger.

mixture $\left(T_{\text {Mix }}\right)$, the inlet oil $\left(T_{\text {in }}\right)$, and the outlet oil $\left(T_{\text {out }}\right)$ from the heat storage vessel in the solidification process. Average temperatures of the PCM, and inlet and outlet temperatures of the oil in the heat storage vessel, were measured by installing thermocouples in each part and the temperature histories were recorded with the data logger. The temperature histories of the mixture showed that the temperature declined from 0 to $7 \mathrm{~min}$ with the sensible heat release. The temperature of the mixture in the latent heat part was $150^{\circ} \mathrm{C}$. The temperature of the mixture decreased quickly at $\sim 7$ min because the PCM mixture solidified quickly at this point. The solidification process ended at $\sim 40 \mathrm{~min}$.

In the melting and solidification processes, the amount of heat stored and released are as follows:

$$
\begin{gathered}
Q_{\mathrm{M}}=\int_{t_{\mathrm{b}}}^{t_{\mathrm{e}}} f_{\text {oil }} \cdot C_{\text {Poil }} \Delta T \mathrm{~d} t \\
Q_{\mathrm{S}}=\int_{t_{\mathrm{b}}}^{t_{\mathrm{e}}} f_{\text {oil }} \cdot C_{\text {Poil }} \Delta T \mathrm{~d} t
\end{gathered}
$$

where $Q_{\mathrm{M}}$ is the amount of heat stored (kJ), $Q_{\mathrm{S}}$ is the amount of heat released $(\mathrm{kJ}), t_{\mathrm{b}}, t_{\mathrm{e}}$ are the beginning and ending time of experiment (min), $f_{\mathrm{oil}}$ is the flow rate of the heat transfer oil $(\mathrm{kg} / \mathrm{min}), C_{\text {poil }}$ is the specific heat of the heat transfer oil $(\mathrm{kJ} / \mathrm{kgK}), \Delta T$ is the temperature difference between the inlet and outlet $\left({ }^{\circ} \mathrm{C}\right)$.

The amount of theoretical heat stored and released can be calculated as follows:

$$
\begin{gathered}
Q_{\mathrm{PCM}}=m_{\mathrm{pcm}} C_{\mathrm{Pl}}\left(T_{\mathrm{b}}-T_{\mathrm{m}}\right)+L m_{\mathrm{pcm}}+m_{\mathrm{pcm}} C_{\mathrm{Ps}}\left(T_{\mathrm{m}}-T_{\mathrm{e}}\right) \\
Q_{\mathrm{oil}}=m_{\mathrm{oil}} C_{\mathrm{Poil}}\left(T_{\mathrm{b}}-T_{\mathrm{e}}\right) \\
Q_{\mathrm{ts}}=m_{\mathrm{ts}} C_{\mathrm{Pts}}\left(T_{\mathrm{b}}-T_{\mathrm{e}}\right) \\
Q_{\mathrm{th}}=Q_{\mathrm{PCM}}+Q_{\mathrm{oil}}+Q_{\mathrm{ts}}
\end{gathered}
$$

where $Q_{\mathrm{PCM}}$ is the amount of sensible heat and the amount of latent heat in the PCM (kJ). $Q_{\text {oil }}$ is the amount of sensible heat of oil (kJ). $Q_{\mathrm{ts}}$ is the amount of sensible heat of test section material $(\mathrm{kJ}) . m_{\mathrm{pcm}}$ is the mass of PCM $(\mathrm{kg}), C_{\mathrm{Pl}}$ is the specific heat of liquid PCM $(\mathrm{kJ} / \mathrm{kgK}), T_{\mathrm{b}}, T_{\mathrm{e}}$ are the temperature at the beginning 
and end of the experiment $\left({ }^{\circ} \mathrm{C}\right), T_{\mathrm{m}}$ is the melting temperature of PCM $\left({ }^{\circ} \mathrm{C}\right), L$ is the latent heat of PCM $(\mathrm{kJ} / \mathrm{kg}), C_{\mathrm{Ps}}$ is the specific heat of solid PCM $(\mathrm{kJ} / \mathrm{kgK})$, $m_{\text {oil }}$ is the mass of oil inside of the heat storage vessel $(\mathrm{kg}), m_{\mathrm{ts}}$ is the mass of the construction material of heat storage vessel $(\mathrm{kg}), C_{\mathrm{Pts}}$ is the specific heat of the construction material of heat storage vessel $(\mathrm{kJ} / \mathrm{kgK})$.

During the solidification process, theoretical heat is $Q_{\mathrm{PCM}}=1441.216 \mathrm{~kJ}, Q_{\mathrm{oil}}=$ $1195.75 \mathrm{~kJ}, Q_{\mathrm{ts}}=981 \mathrm{~kJ}$ and $Q_{\mathrm{th}}=3617 \mathrm{~kJ}$. During the melting process, theoretical heat is $Q_{\mathrm{PCM}}=1466 \mathrm{~kJ}, Q_{\mathrm{oil}}=1258.7 \mathrm{~kJ}, Q_{\mathrm{ts}}=1032.6 \mathrm{~kJ}$ and $Q_{\mathrm{th}}=3757 \mathrm{~kJ}$.

For calculating the theoretical amount of heat during the solidification process, the temperatures of heat transfer oil at the beginning and end of the experiment were $190^{\circ} \mathrm{C}$ and $95^{\circ} \mathrm{C}$ respectively. During the melting process, the temperatures of heat transfer oil at the beginning and end of the experiment were $90^{\circ} \mathrm{C}$ and $190^{\circ} \mathrm{C}$ of oil respectively.

Figure 8 shows the amount of heat released at oil flow rates of 1.0, and 2.0 $\mathrm{kg} / \mathrm{min}$, without the partition plate, with the partition plate and with the metal fiber. From this graph, it can be seen that the amount of heat released with a 1.0 $\mathrm{kg} / \mathrm{min}$ oil flow rate was nearly same without the partition plate, with the partition plate and with the metal fiber. At an oil flow rate of $2.0 \mathrm{~kg} / \mathrm{min}$, the amount of heat released in the solidification process using the metal fiber was less than that in the two other experiments. Thus, using the metal fiber may prevent convection heat transfer and decrease the heat transfer area because of the decreased height of solidified PCM on solidification.

Figure 9 and Figure 10 show the completion time and total amount of heat released in the solidification process. During the solidification process, the completion time and total amount of heat released decreased with increasing flow rate of oil. The total amount of heat released without and with the perforated partition plate was nearly the same. However, the total amount of heat released decreased slightly when using the metal fiber.

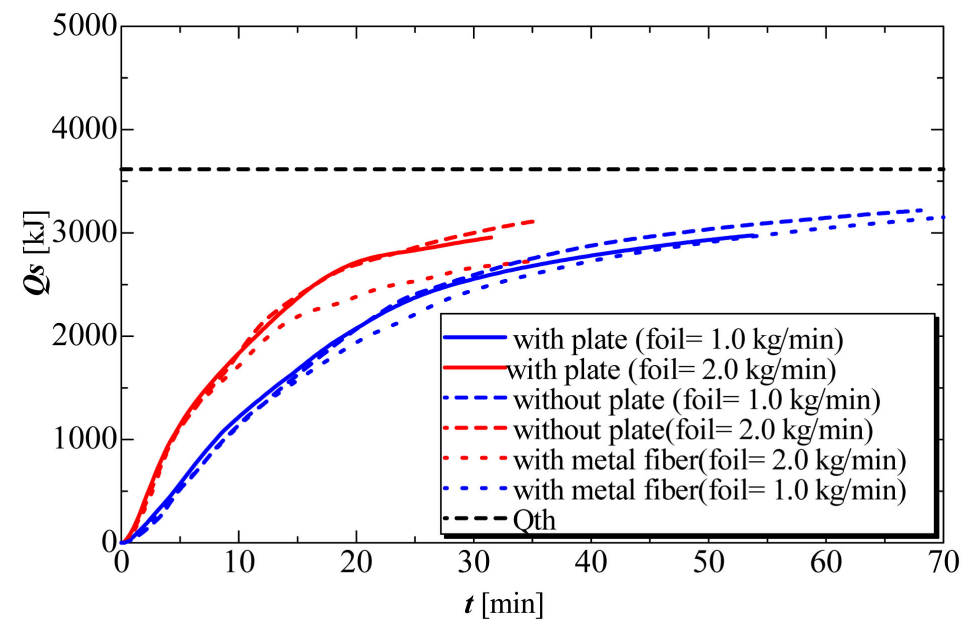

Figure 8. Amount of heat released during the solidification process without perforated partition plate, with perforated partition plate, and with the metal fiber with different oil flow rates. 


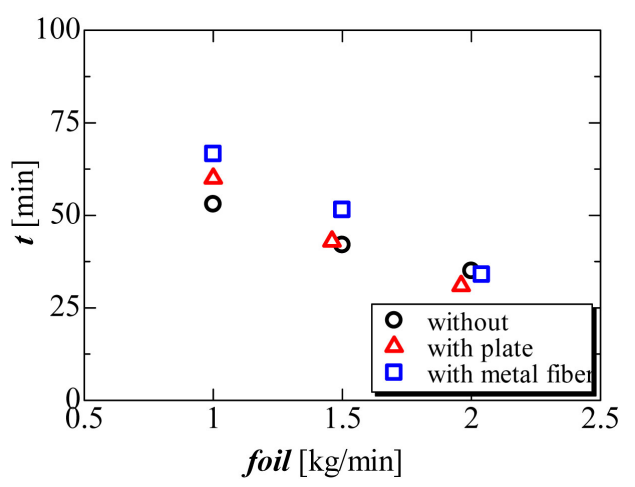

Figure 9. Completion time of the solidification process without perforated partition plate, with perforated partition plate, and with metal fiber at three different flow rates of oil.

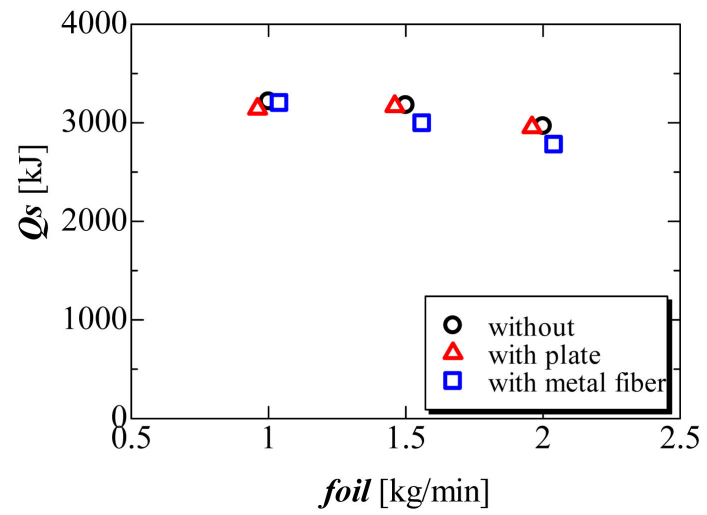

Figure. 10. Total amount of heat released during the solidification process without perforated partition plate, with perforated partition plate, and with metal fiber with three different flow rates of oil.

Thus, using the metal fiber may prevent convective heat transfer and decrease the heat transfer area because of the decreased height of solidified PCM in the solidification process.

Figure 11 shows a mechanism of breaking PCM coated oil droplets in the solidification process (a) with the perforated partition plate and (b) with the metal fiber. When heat transfer oil flows through the PCM region in the solidification process, the PCM forms a thin layer on the outside of the oil droplets. Without perforated partition plate and metal fiber in the heat storage vessel, thin layer of PCM coated oil droplets were broken only at the interface of the liquid PCM and oil region and this interface can move up with increasing of oil flow rate. At that time the solidified height of the PCM will be increased. By using the perforated partition plate, PCM coated oil droplets float on the interface between the oil and PCM, and these oil droplets are pushed next to the other floating oil droplets because of continuous flowing of oil from the bottom of heat storage vessel. And then, the pushed oil droplets will collide to the surface of the perforated partition plate and it will be broken. So it could prevent to increase the solidified height of the PCM, Figure 11(a). When inserting the metal fiber at the PCM region of the heat storage vessel, the PCM coated oil droplets flowed through the 


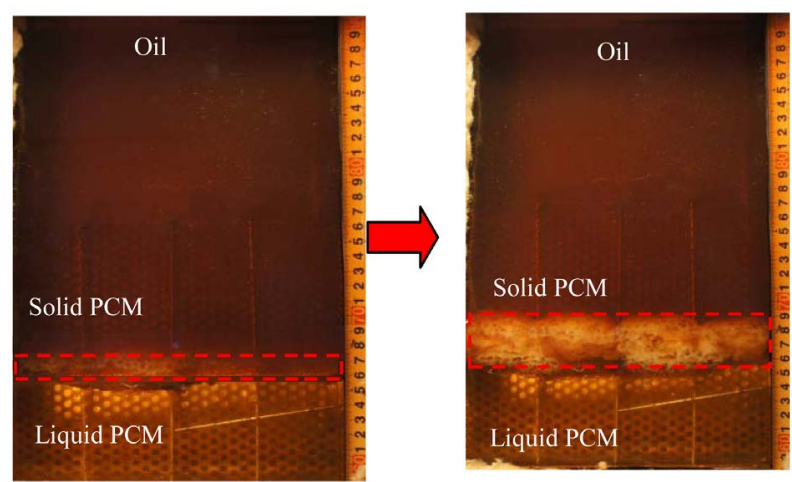

(a)

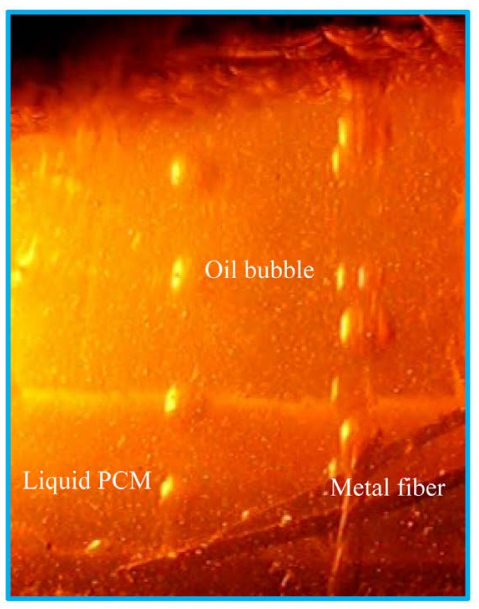

(b)

Figure 11. Mechanism of breaking PCM coated oil droplets with the perforated partition plate and with metal fiber. (a) with perforated partition plate; (b) with metal fiber.

metal fiber and at that time the metal fiber divided the PCM coated oil droplets to solidified PCM and oil. The solidified PCM left at the interface of the liquid PCM and oil, and then oil flowed to the upper part of the heat storage vessel Figure 11(b). This mechanism can decrease the solidification height of PCM. The metal fiber is distributed through all parts of the PCM region better than with the perforated partition plate. Thus, the metal fiber can break more PCM-coated oil droplets than the perforated partition plate. As a result, the metal fiber decreases the solidification height of the PCM more effectively.

\subsection{Melting Process}

Figure 12 shows the melting behavior of the latent heat storage mixture PCM with an oil flow rate of $2.0 \mathrm{~kg} / \mathrm{min}$ (a) without the perforated partition plate, (b) with the perforated partition plate, and (c) with the metal fiber. After finishing the solidification process, it is found that the PCM solidified porous layer at the upper portion and dense layer at the lower portion. During the melting process, oil flows through the formed paths from the porous zone of the solidified PCM. The PCM starts to melt from the upper part of the solidified PCM. After that, 


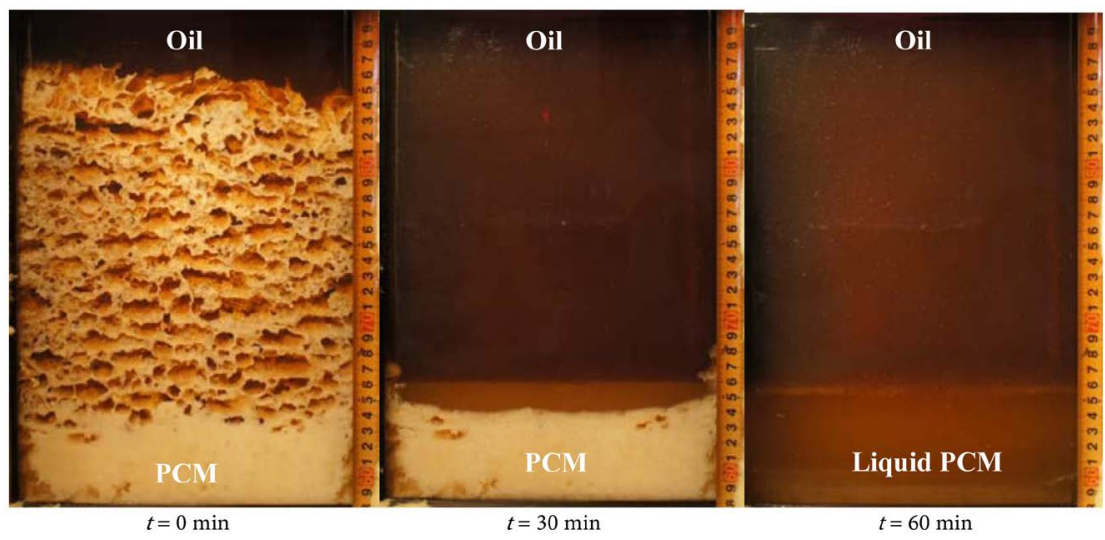

(a)

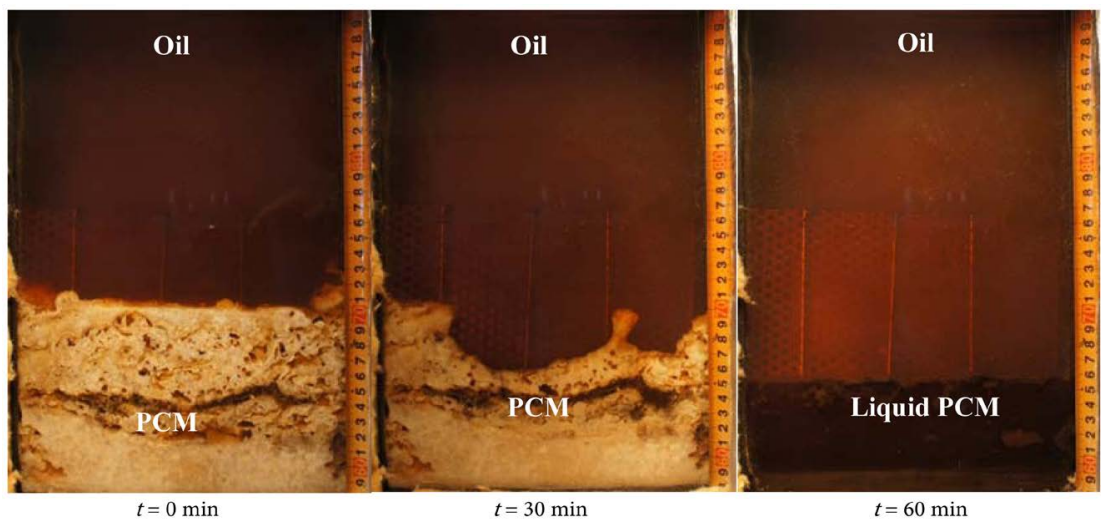

(b)
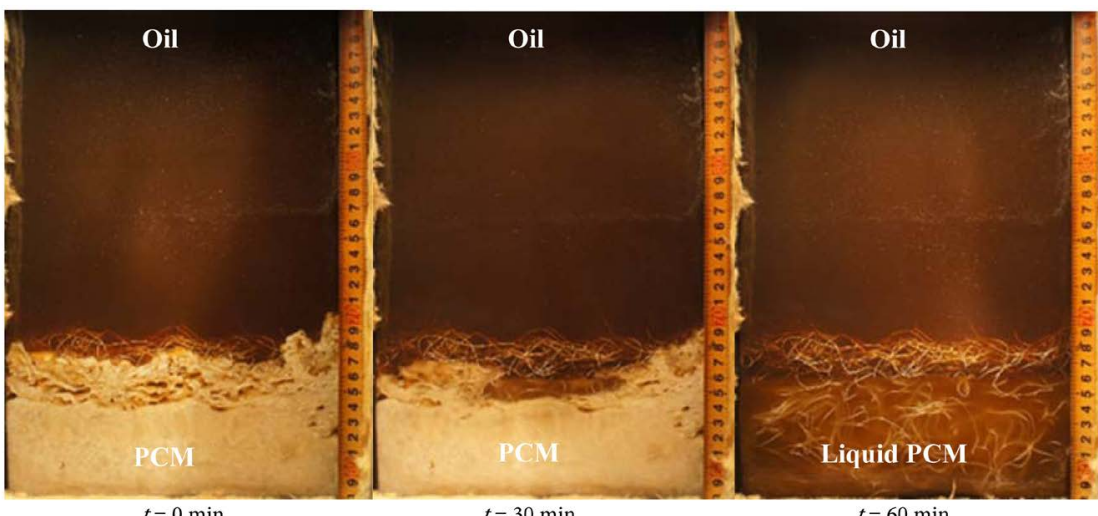

(c)

Figure 12. Visual observation of the melting process. This is the photos of PCM's conditions at 0,30 , and $60 \mathrm{~min}$ during the melting process (a) without perforated partition plate $\left(f_{\text {oil }}=2.0 \mathrm{~kg} / \mathrm{min}\right)$; (b) with perforated partition plate $\left(f_{\text {oil }}=2.0 \mathrm{~kg} / \mathrm{min}\right)$; and (c) with metal fiber $\left(f_{\mathrm{oil}}=2.0 \mathrm{~kg} / \mathrm{min}\right)$.

the amount of melting PCM increases with time from top to bottom in the heat storage vessel. The porous solidified layer has a large surface area per unit volume and is easy to heat exchange from oil even though the oil was flow from the bottom of heat storage vessel. The melting process has finished when the outlet temperature of the oil reaches $195^{\circ} \mathrm{C}$. 
Figure 13 shows the temperature histories of the PCM without the perforated partition plate in the heat storage vessel with an oil flow rate $2.0 \mathrm{~kg} / \mathrm{min}$. Before starting the melting process, the temperature of the inlet, outlet, PCM and heat storage vessel were maintained at $90^{\circ} \mathrm{C}$. To melt the mixture in the test section, silicone oil at $200^{\circ} \mathrm{C}$ from the high-temperature oil bath was pumped through the inlet of the heat storage vessel. At the start of the melting process, the temperature of the inlet oil is changed immediately from $90^{\circ} \mathrm{C}$ to $200^{\circ} \mathrm{C}$. Because of this reason, the temperature lines of inlet and outlet oil increased sharply at the start of melting process. The melting process was done at $60 \mathrm{~min}$.

Figure 14 shows the amount of heat stored during the melting process. The completion time of the melting process was shortened with increasing oil flow rate. The melting process finished when the outlet temperature of the oil reached $195^{\circ} \mathrm{C}$. From Figure 14, the total amounts of heat storage in the melting process without the perforated partition plate, with the perforated partition plate, and with the aluminum metal fiber were nearly the same.

Figure 15 and Figure 16 show the completion time and total amount of heat storage during the melting process without the perforated partition plate, with

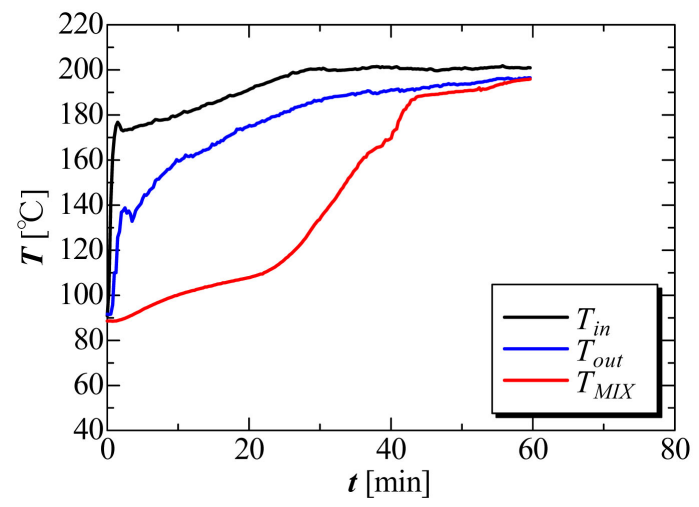

Figure 13. Temperature histories of inlet oil, out oil, and the PCM mixture of the melting process that were recorded using data logger.

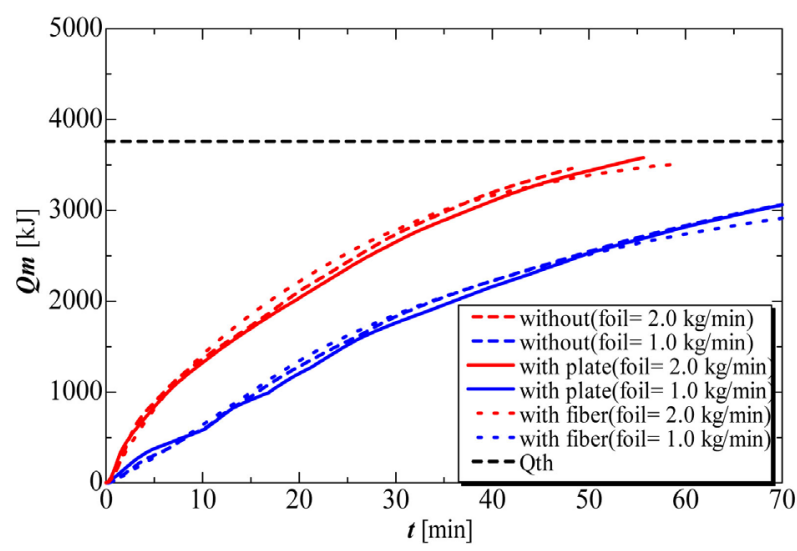

Figure 14. Amount of heat stored during the melting process without perforated partition plate, with perforated partition plate, and with metal fiber at two different oil flow rates. 


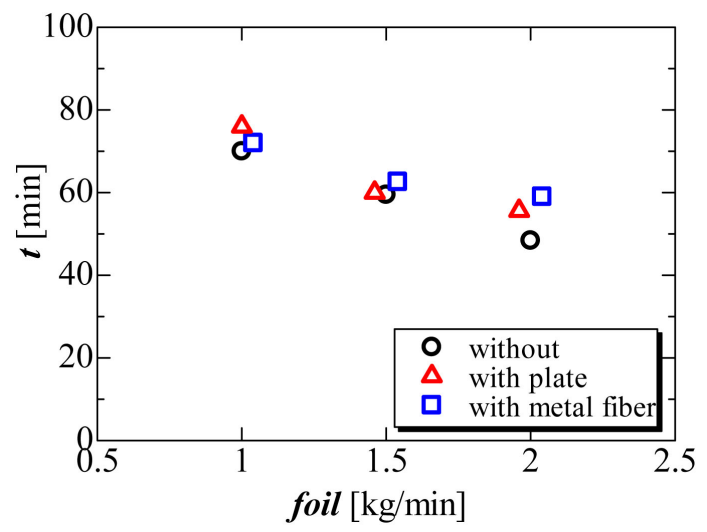

Figure 15. Completion time of the melting process without perforated partition plate, with perforated partition plate, and with metal fiber with three different flow rates of oil.

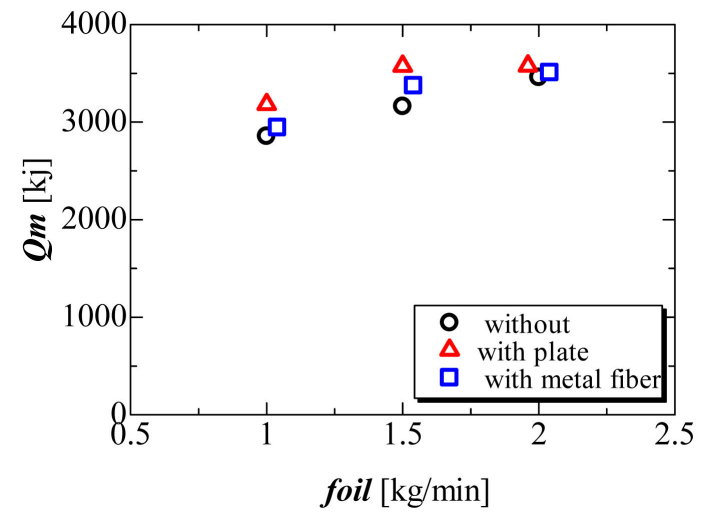

Figure 16. Total amount of heat storage during the melting process without perforated partition plate, with perforated partition plate, and with metal fiber with three different flow rates of oil.

the perforated partition plate and with the metal fiber. The completion time was shortened by increasing the oil flow rate. The completion times using the perforated partition plate and the metal fiber were longer than without the perforated partition plate. This is likely because they reduced convective heat transfer in the melting process. When using the perforated partition plate or the metal fiber, the total amount of heat storage was increased versus without the perforated partition plate. They prevent convective heat transfer and the solidified height of the PCM decreases as does the heat transfer area. This means that slightly more heat is needed in these two processes to melt all the PCM.

\section{Conclusions}

The characteristics of heat storage and release of a mannitol and erythritol mixture with various oil flow rates were investigated, and the solidified height was controlled by installing a perforated partition plate in the PCM region in the latent heat storage system. We also installed aluminum metal fiber in the PCM region and the results were compared between experiments without the perforated partition plate, with the perforated partition plate, and with the metal fiber. 
In the solidification process, the solidified height of the PCM was $270 \mathrm{~mm}$ without the perforated partition plate and $150 \mathrm{~mm}$ with the perforated partition plate. The formed oil droplets were broken by the surface of the perforated partition plate, so may have reduced the solidified height of the PCM. Using the metal fiber, the solidified height was $100 \mathrm{~mm}$, representing a further decrease. The metal fiber was better distributed in the PCM region and PCM-coated oil droplets were broken more by the metal fiber.

In the melting process, oil directly exchanges heat with a porous zone of solidified PCM. The PCM melting begins at the upper part of the PCM and then the amount of melted PCM increases with time from top to bottom. The completion time of the melting process was shortened with increased oil flow rate and was lengthened using the perforated partition plate and metal fiber versus with no perforated partition plate. Use of the metal fiber was an effective way to decrease the solidification height of the PCM in the solidification process.

\section{Acknowledgements}

Authors would like to thank Yoshitaka Takase, Mazakazu Shinoda, master students of the Okayama University, for helping our experiment works.

\section{References}

[1] Inaba, H. and Sato, K. (2000) Latent Cold Heat Energy Storage Characteristics by Means of Direct-Contact-Freezing between Oil Droplets and Cold Water Solution. International Journal of Heat and Mass Transfer, 40, 3189-3200. https://doi.org/10.1016/S0017-9310(96)00366-3

[2] Kiatsiriroat, T., Vithayasai, S., Vorayos, N., Nuntaphan, A. and Vorayos, N. (2003) Heat Transfer Prediction for a Direct Contact Ice Thermal Energy Storage. Energy Conversion and Management, 44, 497-508. https://doi.org/10.1016/S0196-8904(02)00077-8

[3] Kiatsiriroat, T., Tiansuwan, J., Suparos, T. and Na Thalang, K. (2000) Performance Analysis of a Direct-Contact Thermal Energy Storage Solidification. Renewable Energy, 20, 195-206. https://doi.org/10.1016/S0960-1481(99)00110-X

[4] Kaizawa, A., Kamano, H., Kawai, A., Jozuka, T., Senda, T., Maruoka, N. and Akiyama, T. (2008) Thermal and Flow Behaviors in Heat Transportation Container Using Phase Change Material. Energy Conversion and Management, 49, 698-706. https://doi.org/10.1016/j.enconman.2007.07.022

[5] Nomura, T., Tsubota, M., Sagara, A. and Okinaka, N. (2013) Performance Analysis of Heat Storage of Direct-Contact Heat Exchanger with Phase Change Material. Applied Thermal Engineering, 58, 108-113. https://doi.org/10.1016/j.applthermaleng.2013.03.041

[6] Baran, G. and Sari, A. (2003) Phase Change and Heat Transfer Characteristics of a Eutectic Mixture of Palmitic and Stearic Acids as PCM in a Latent Heat Storage System. Energy Conversion and Management, 44, 3227-3246. https://doi.org/10.1016/S0196-8904(03)00104-3

[7] Hidaka, H., Yamazaki, M., Yabe, M., Kakiuchi, H., Pona, E., Kojima, Y. and Matsuda, H.(2004) New PCMs Prepared from Erythritol-Polyalcohols Mixtures for Latent Heat Storage between $80^{\circ} \mathrm{C}$ and $100^{\circ} \mathrm{C}$. Journal of Chemical Engineering of Japan, 37, 1155-1162. https://doi.org/10.1252/jcej.37.1155 
[8] Gubanova, T.V. and Garkushin, I.K. (2007) LiF-LiCl-LiVO $-\mathrm{Li}_{2} \mathrm{SO}_{4}-\mathrm{Li}_{2} \mathrm{MoO}_{4}$ System. Russian Journal of Inorganic Chemistry, 52, 1624-1628. https://doi.org/10.1134/S0036023607100269

[9] Horibe, A., Jang, H., Haruki, N., Sano, Y., Habara, H. and Takahashi, K. (2015) Melting and Solidification Heat Transfer Characteristics of Phase Change Material in the Latent Heat Storage Vessel: Effect of Perforated Partition Plate. International Journal of Heat and Mass Transfer, 82, 259-266. https://doi.org/10.1016/j.ijheatmasstransfer.2014.11.050

[10] Horibe, A., Yu, J., Haruki, N., Kaneda, A., Machida, A. and Kato, A.M. (2011) Melting Characteristic of Mixture of Two Kinds of Latent Heat Storage Material. Netsu Bussei, 25, 136-142. https://doi.org/10.2963/jjtp.25.136

[11] Sumitomo, H., Kado, S., Nozalo, T., Fushinobu, K. and Okazaki, K. (2015) Energy Enhancement of Low Temperature Waste Heat by Methanol Steam Reforming for Hydrogen Production. $8^{\text {th }}$ Asian Hydrogen Energy Conference, Beijing, China, 26-27 May 2005, 26-27.

[12] Horibe, A., Yu, J., Haruki, N. and Kamei, T. (2010) Fundamental Study on the Melting and Solidification Characteristic of Two Latent Heat Storage Materials and Their Compounds. 9th Asian Thermo-physical Properties Conference ATPC, Beijing, 19-22 October 2010, ATPC109071.

\section{Scientific Research Publishing}

\section{Submit or recommend next manuscript to SCIRP and we will provide best} service for you:

Accepting pre-submission inquiries through Email, Facebook, LinkedIn, Twitter, etc. A wide selection of journals (inclusive of 9 subjects, more than 200 journals) Providing 24-hour high-quality service User-friendly online submission system Fair and swift peer-review system Efficient typesetting and proofreading procedure Display of the result of downloads and visits, as well as the number of cited articles Maximum dissemination of your research work

Submit your manuscript at: http://papersubmission.scirp.org/ Or contact jpee@scirp.org 